\title{
Modeling and Real-Time Simulation of Large Hydropower Plant
}

\author{
Sonam Dorji ${ }^{\text {a }}$ \\ ${ }^{a}$ Jigme Namgyel Engineering College, Dewathang, Samdrup Jongkhar, Bhutan
}

Received: 17 December 2018; Accepted: 15 February 2019; Published: 08 May 2019

\begin{abstract}
In this paper, modeling and simulation of large hydropower plant in real-time platform named Real-Time Laboratory (RT-LAB) is carried out. First, a hydropower plant model consisting of nonlinear hydro turbine with PID governor and synchronous generator (SG) with DC1A excitation system and connected to grid is developed in MATLAB/Simulink environment. This model is then simulated in RT-LAB after the modification of MATLAB/Simulink model required for suitable operation in RT-LAB environment. Finally, the real-time simulation of hydropower plant when subjected to disturbances of load addition, reduction of load and short circuit fault analysis is presented and discussed.
\end{abstract}

Index Terms: Real-time laboratory (RT-LAB), hydropower plant, synchronous generator, real-time simulation, nonlinear hydro turbine.

(C) 2019 Published by MECS Publisher. Selection and/or peer review under responsibility of the Research Association of Modern Education and Computer Science.

\section{Introduction}

Hydropower is a clean, predictable, cost competitive and highest efficient convertible renewable energy source. The development of hydropower is increasing due to the environmental concern caused by the use of traditional energy and rapid depletion of traditional energy. Moreover, the demand of electricity in the modern market is increased significantly due to the rapid industrialization and improving the living standards across the globe. Therefore, the development of clean renewable energy like hydropower becomes necessary. The typical hydropower plant consists of reservoir, tunnel, surge tank, penstock, power house, and electrical power substation as shown in Fig. 1 below where reservoir stores the water and creates head for the generation of power; penstocks carry the water to turbines for the production of mechanical power which drives the synchronous generator to generate electricity. The power generated by hydropower depends on the net head available at the site and quantity of water flowing. Modeling and simulation becomes very important in the

\footnotetext{
* Corresponding author.

E-mail address:
} 
research work nowadays. Most of the research works on modeling and simulation of hydropower plant involving different models of hydro turbine has been carried out by many authors and researchers.

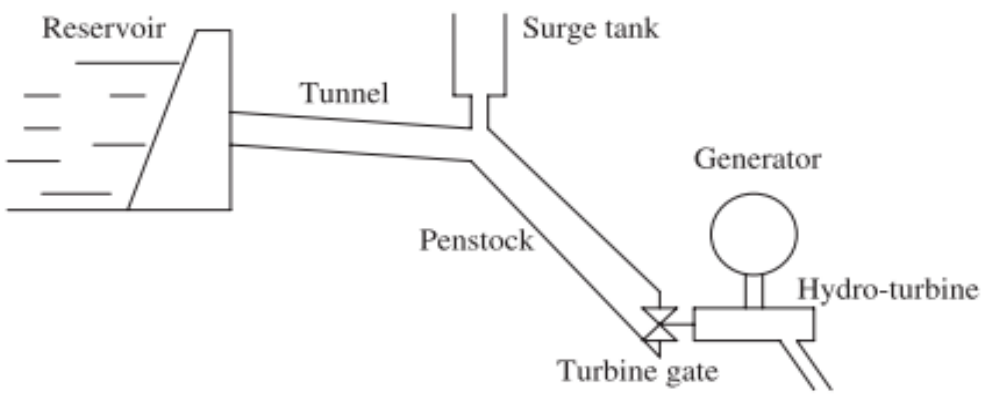

Fig.1. Layout Diagram of Hydropower Plant [1]

Ref. [2] introduced the nonlinear hydro turbine model for the dynamic analysis of hydropower plant. The modeling and real-time simulation of different types of hydro turbine and governor model was performed in ref. [3]. They developed the hydro turbine and governor model in MATLAB/Simulink and then the model was simulated in RT-LAB environment. In this paper, simulation of hydropower plant in real-time platform named Real-Time Laboratory (RT-LAB) [4] developed by OPAL-RT Technologies, Canada, is used to simulate the dynamic behaviour of hydropower plant. RT-LAB can separate the complex system into simple subsystems and run parallel in multi-processor. Authors in [3] developed four different types of hydro turbine model including nonlinear analytical hydro turbine model for studying the dynamic behavior of the system. Jaeger et al. [4] illustrated the nonlinear model of a hydro turbine for dynamic studies with a single turbine and multiple turbines supplied from a common tunnel. Vinatoru \& Iancu [5] presented the possibilities of modeling and simulation of the hydraulic systems and the design of the control system. Zhang et al. [6] discussed the mathematical modeling of a hydro-turbine governing system during the process of load rejection transients and nonlinear dynamic behaviors of the governing system. Author [7] discussed full modeling and control of micro hydro power station based on the nonlinear hydro turbine model using an induction generator (IG) applied in micro-grid systems. The modeling and simulation of Micro Hydro-Diesel hybrid power plants for the operation of standalone system is presented in ref.[8]. Author [9] developed the hydraulic turbine regulating system model for simulations of hydraulic transients of hydro power plant. Simulation studies of different types of excitation system for aged small hydro power plant (SHP) have been carried out under different operating conditions for selecting appropriate excitation system for uprating of age SHP in ref.[10]. The effect of governor parameters of hydro power plant on the speed and load changes for a small disturbance in the power network is investigated in ref.[11].

In this paper, a hydropower plant model consisting of nonlinear hydro turbine with PID governor and synchronous generator with DC1A excitation system is developed in MATLAB/Simulink environment and then the model is simulated in RT-LAB environment for real-time simulation after the required modification for suitable operation in RT-LAB. Finally, the real-time simulation results of hydropower plant when subjected to disturbances of load addition, load reduction and short circuit fault were presented and discussed.

\section{Modeling of Hydropower Plant}

The hydropower plant model developed in MATLAB/Simulink environment as shown in Fig. 2 consists of following components: 
1) Hydro turbine and governor (HTG) model: This model developed the mechanical power required to drive the synchronous generator and control the opening and closing of gate (i.e., Gate position).

2) Synchronous generator (SG) model: This model converts the mechanical energy developed by hydro turbine into electrical energy.

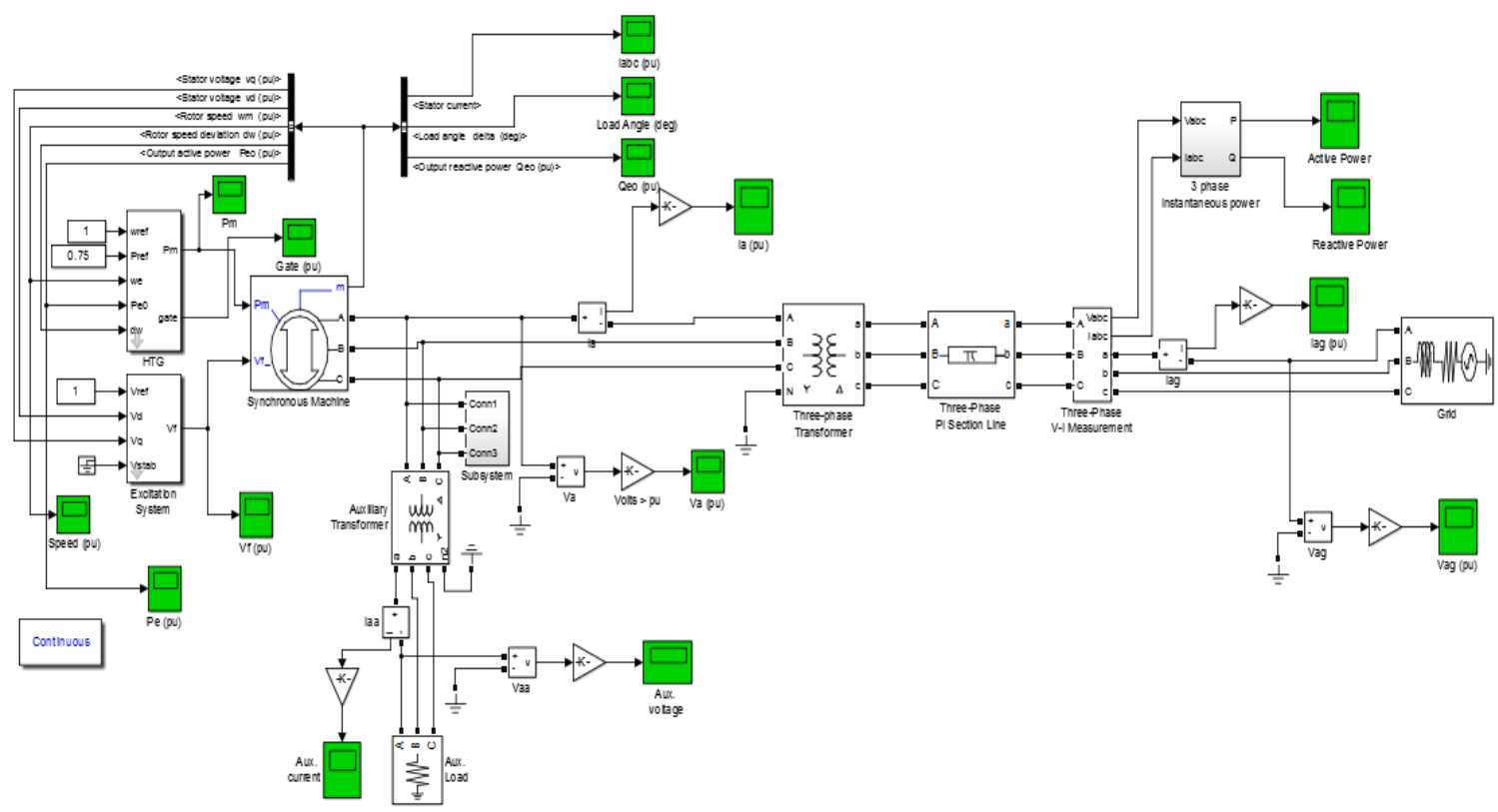

Fig.2. Hydropower Plant Model

3) Excitation system model: This model is used to provide direct current (DC) to the field winding of synchronous generator.

4) Transformer model: This model is used to step up the voltage to transmit the electrical energy for long distances.

5) Grid model: This is the model where the electrical energy is sinking.

\section{RT-LAB Model of Hydropower Plant}

The MATLAB/Simulink model is required to be modified for the real-time simulation of the hydropower plant.

\subsection{Separated RT-LAB model}

The MATLAB/Simulink model is separated into two simple subsystems as shown in Fig. 3 below and it run parallel in multi-processor. 


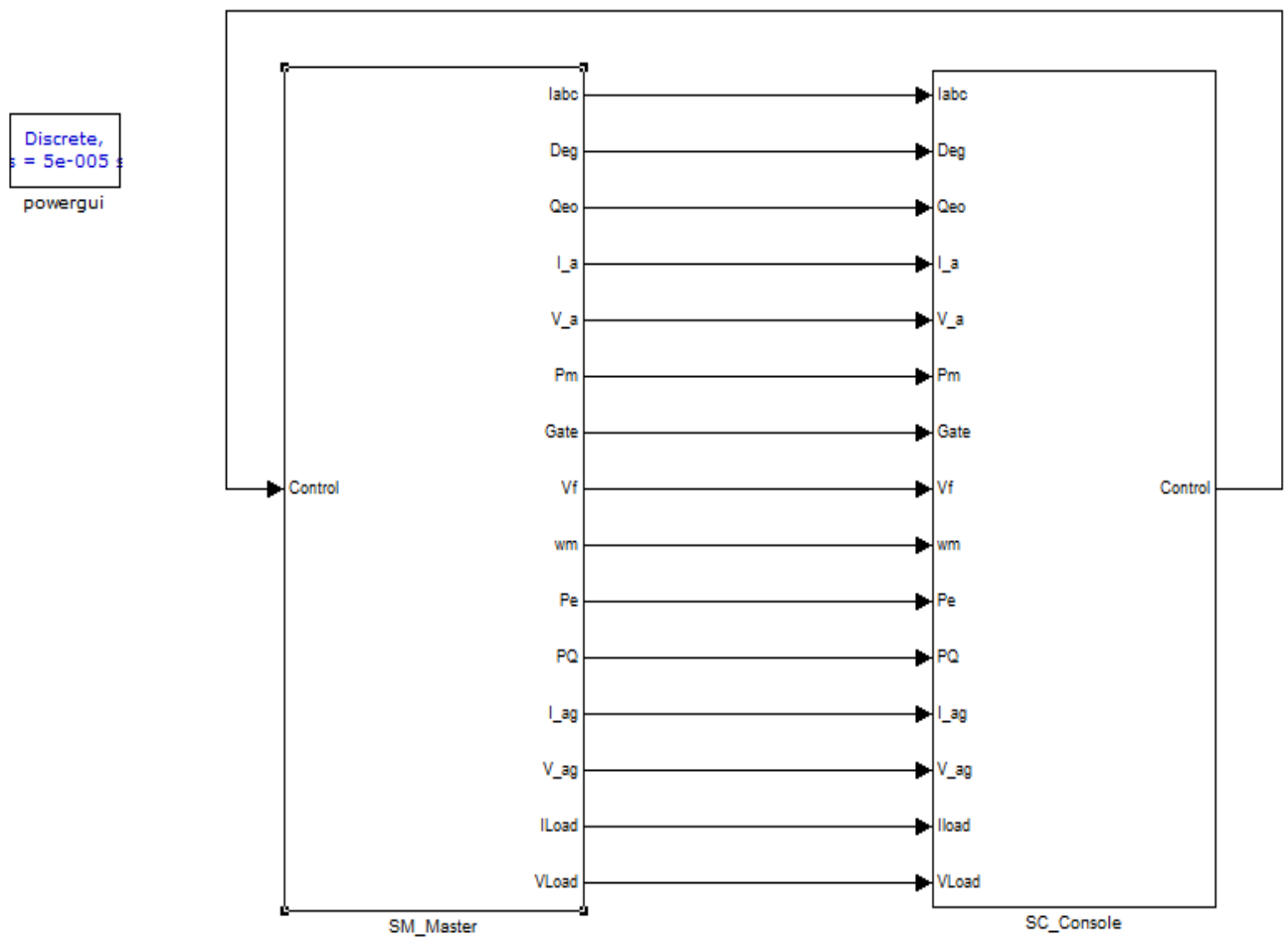

Fig.3. Separated RT-LAB model
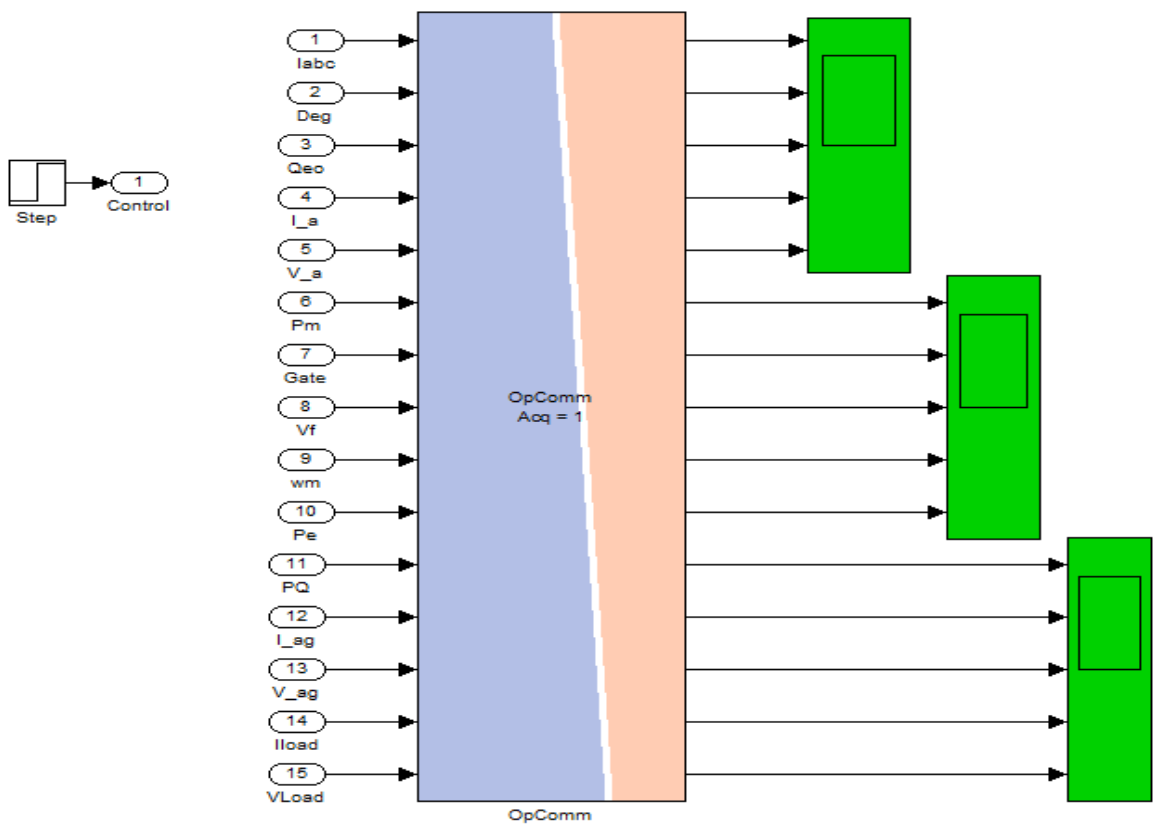

Fig.4. Console Subsystem 


\subsection{Console Subsystem}

The console subsystem is named as SC_Console as shown in Fig. 4 below contains all the displaying, control and accessing blocks. It runs on the host computer which will receive the simulation results and then show the results to the operator through scope [14].

\subsection{Master Subsystem}

The master subsystem is named as SM_Master as shown in Fig. 5 below. It is a computing subsystem which contains all the calculation blocks. It runs on the target machine which has real-time operating system [14]. Therefore, only one master subsystem is allowed in the model.

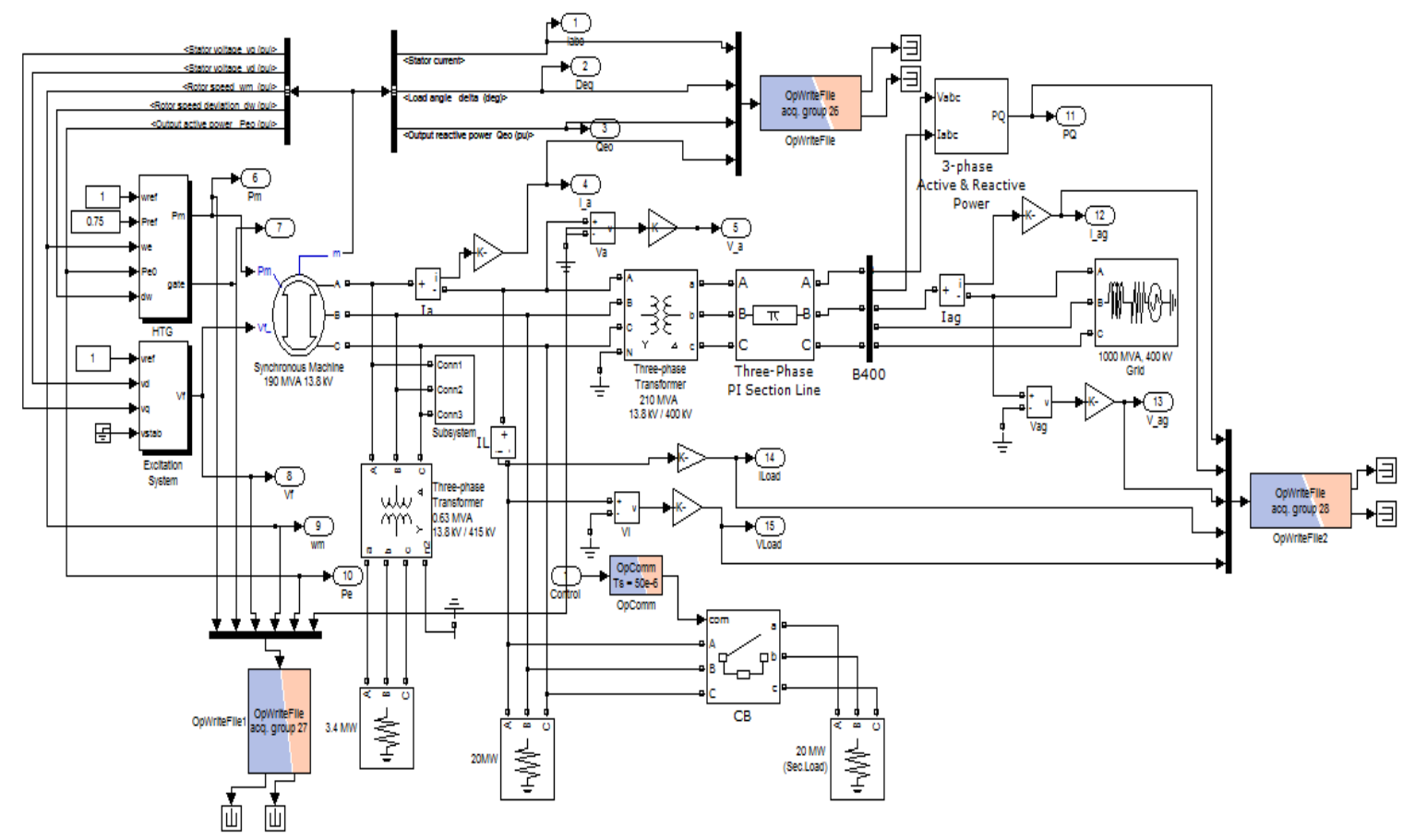

Fig.5. Master Subsystem

RT-LAB uses the OpCom blocks to enable and save communication setup information which includes the communication between the console and master subsystem [15]. The entire input signal should be processed through the OpCom blocks to simulate the model in real-time simulation in RT-LAB environment.

\section{Simulations and Results}

The real-time simulation of dynamic analysis of hydropower plant in RT-LAB environment is performed for the following three cases:
A) Addition of load to the plant.
B) Reduction of load from the plant.
C) Short Circuit Fault 


\subsection{Addition of Load to the Plant}

The single line diagram for load addition is shown in Fig. 6 below.

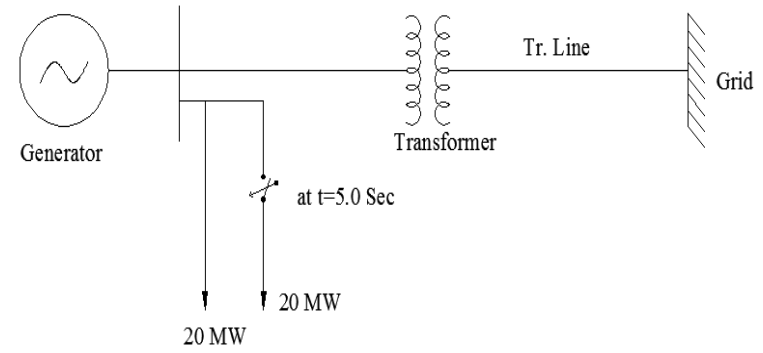

Fig.6. Single Diagram for Load Addition

The total load in the system is $20 \mathrm{MW}$ initially. The disturbances in the system is introduced by adding 20 MW load to the existing $20 \mathrm{MW}$ load at time $\mathrm{t}=5.0$ seconds and simulation is carried out for 10.0 seconds. The following characteristics are obtained during the addition of load to the plant.

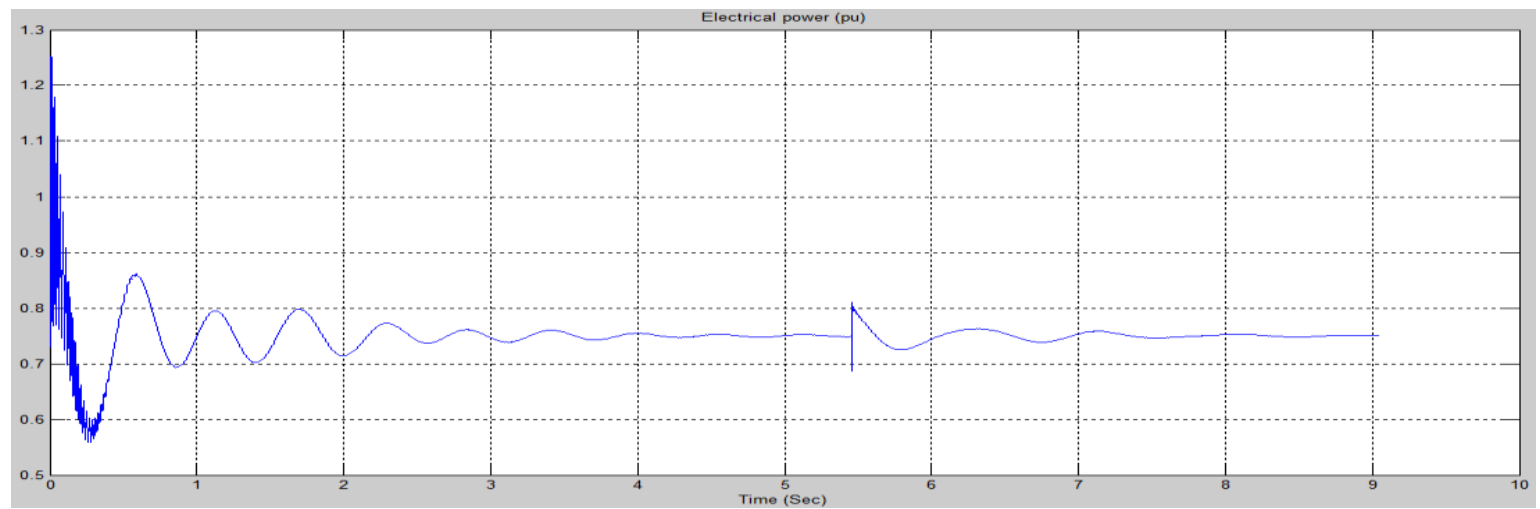

Fig.7. Electrical power Vs time

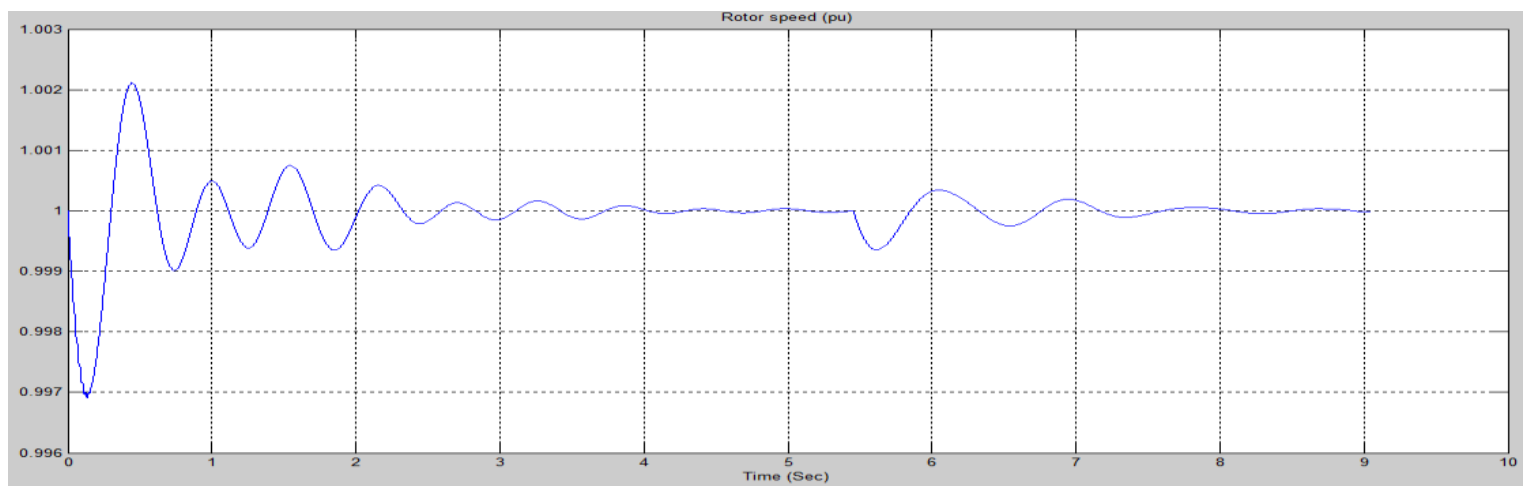

Fig.8. Rotor speed Vs time 


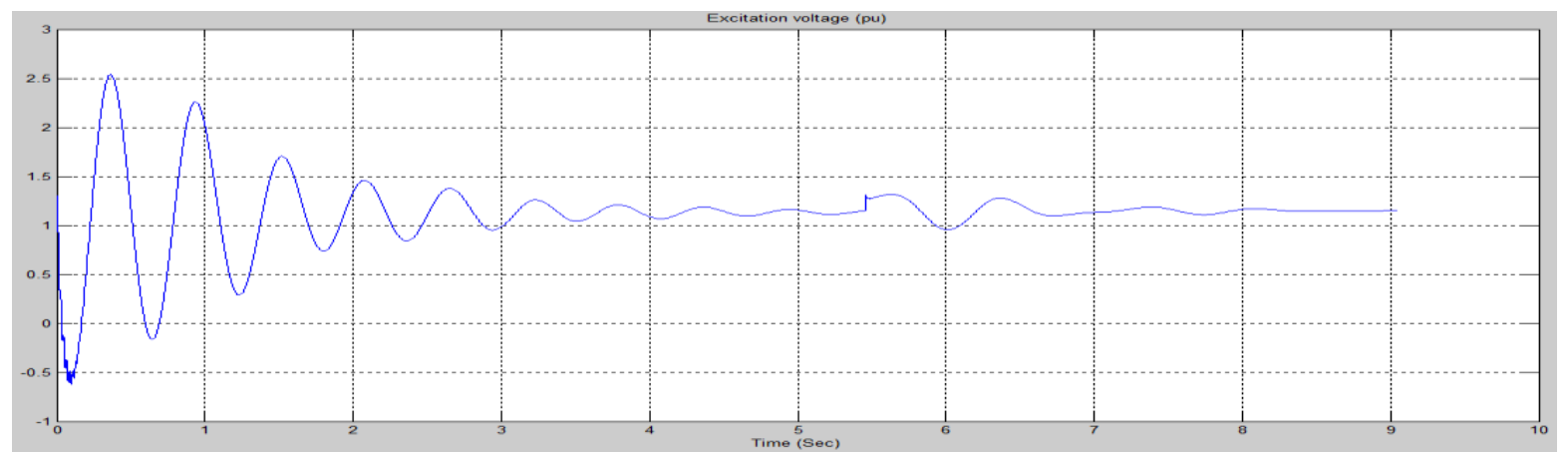

Fig.9. Excitation voltage Vs time

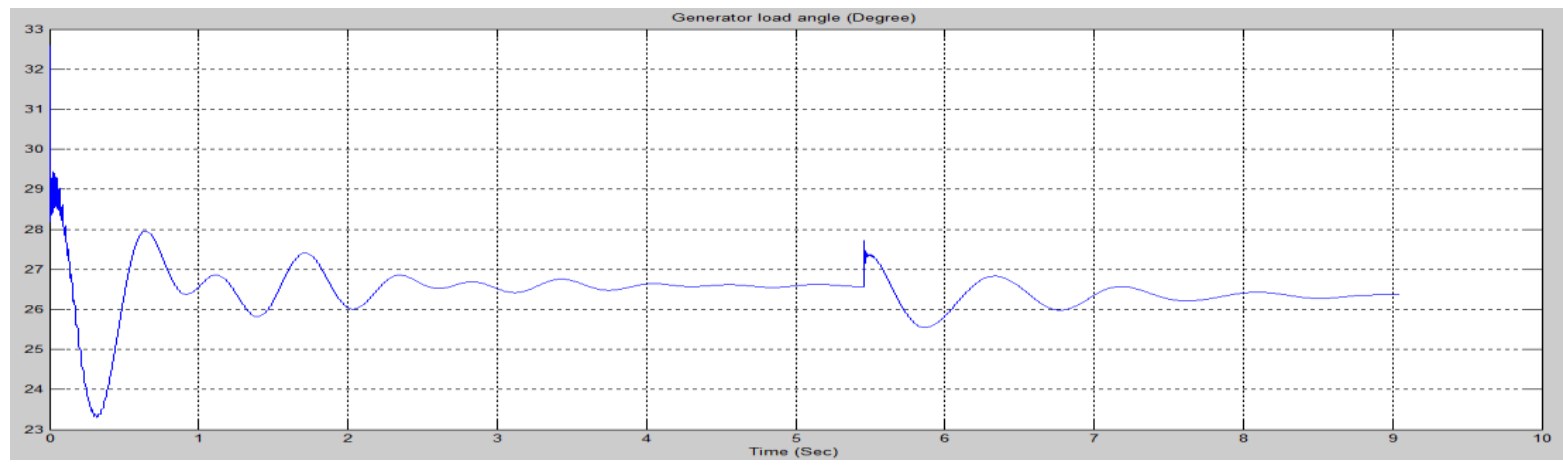

Fig.10. Generator load angle Vs time

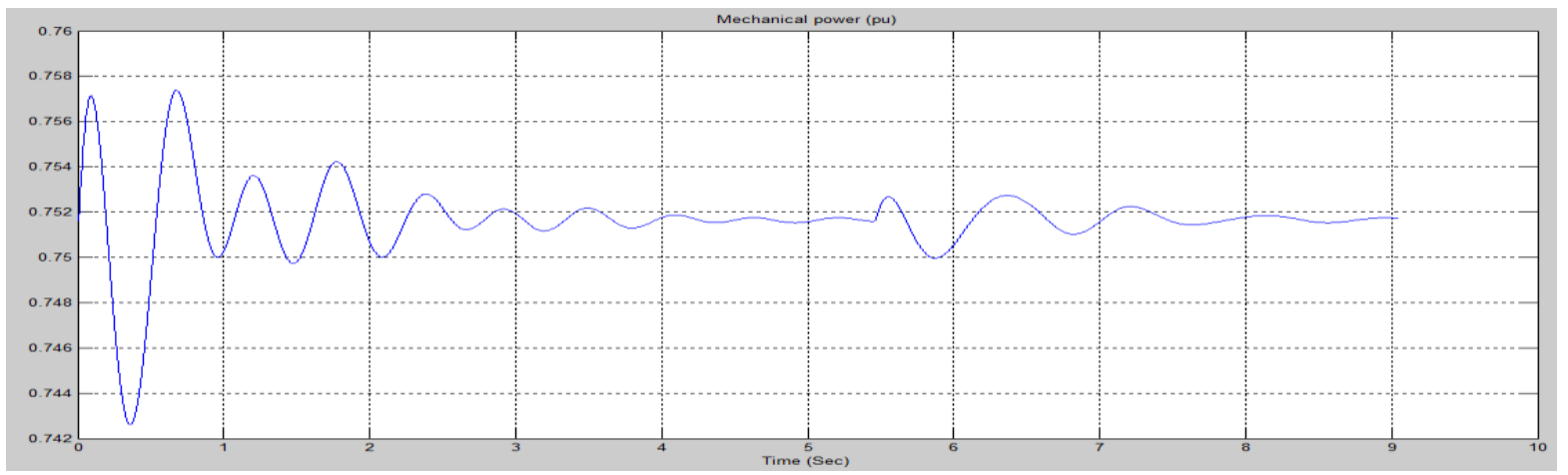

Fig.11. Mechanical power Vs time 


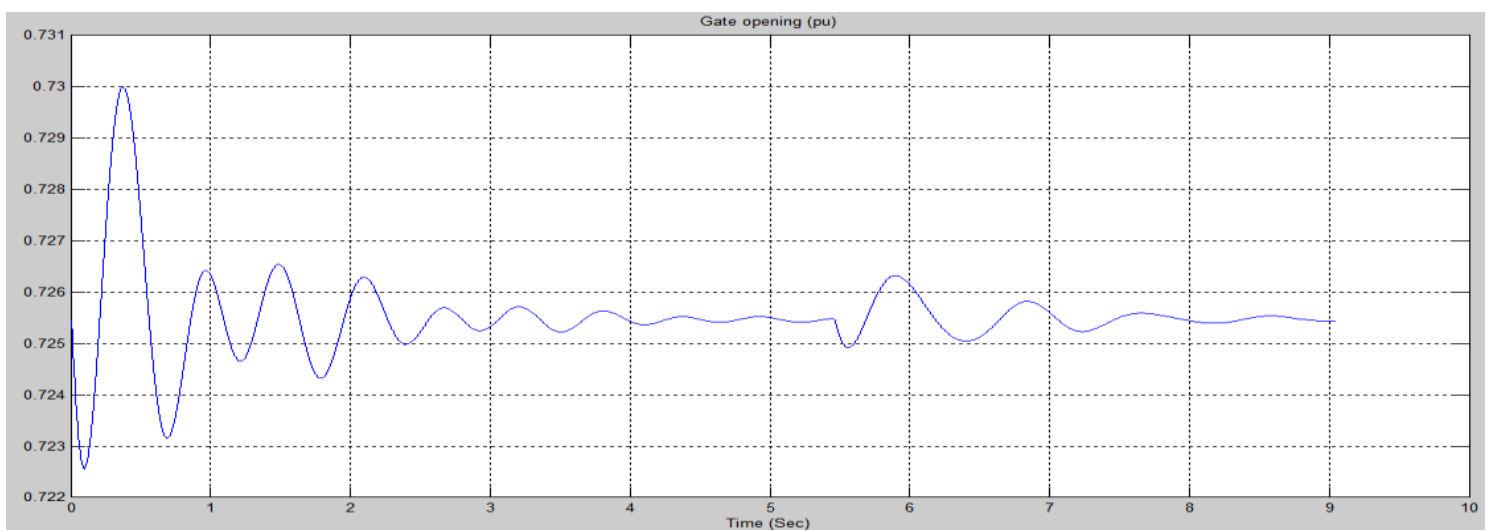

Fig.12. Gate opening Vs time

Form the obtained simulation results shown above for the addition of load to the plant, gives the following observations:

1. The electrical power is increased to 0.8 pu from the initial value of 0.75 pu during the addition of load and it reached to initial steady state value after 7.0 seconds as shown in Fig. 7.

2. The rotor speed is decreased at the time of load addition but it reached to initial steady state value after 7.0 seconds as illustrated in Fig. 8.

3. There is increase in excitation voltage to around $1.3 \mathrm{pu}$ at the time of load addition and it oscillates for around 3.0 seconds and reached to initial steady state value after 8.0 seconds as shown in Fig. 9.

4. The generator load angle is increased to 28 degrees from 27 degrees at the time of addition of load and it oscillates for around 2.0 seconds and the initial steady state value is reached after 7.0 seconds as illustrated in Fig. 10.

5. The mechanical power developed is also increased during the addition of load at $t=5.0$ seconds and it oscillates for around 3.0 seconds and it reached to initial steady state value after 8.0 seconds as shown in Fig. 11.

6. The gate opening is decreased when load is added to the system and it oscillates for around 2.0 seconds and reached back to initial steady state after 7.0 seconds as shown in Fig. 12.

\subsection{Reduction of Load from the Plant}

The single line diagram for load reduction is shown in Fig. 13 below.

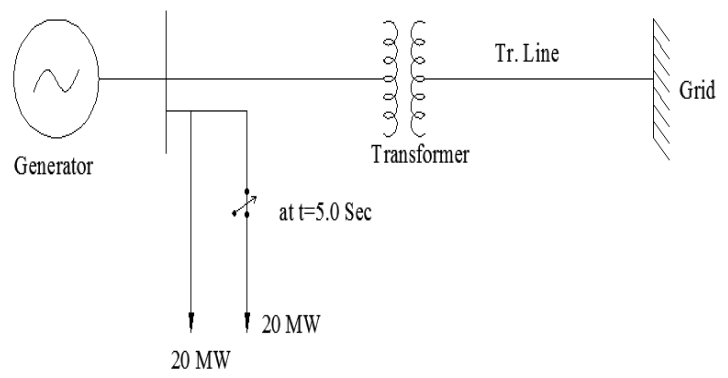

Fig.13. Single Diagram for Load Reduction 
The total load in the system is $40 \mathrm{MW}$ initially. The disturbances in the system is introduced by removing 20 MW load from the $40 \mathrm{MW}$ load at time $\mathrm{t}=5.0$ seconds and simulation is carried out for 10.0 seconds. The following characteristics are obtained during the reduction of load from the plant.

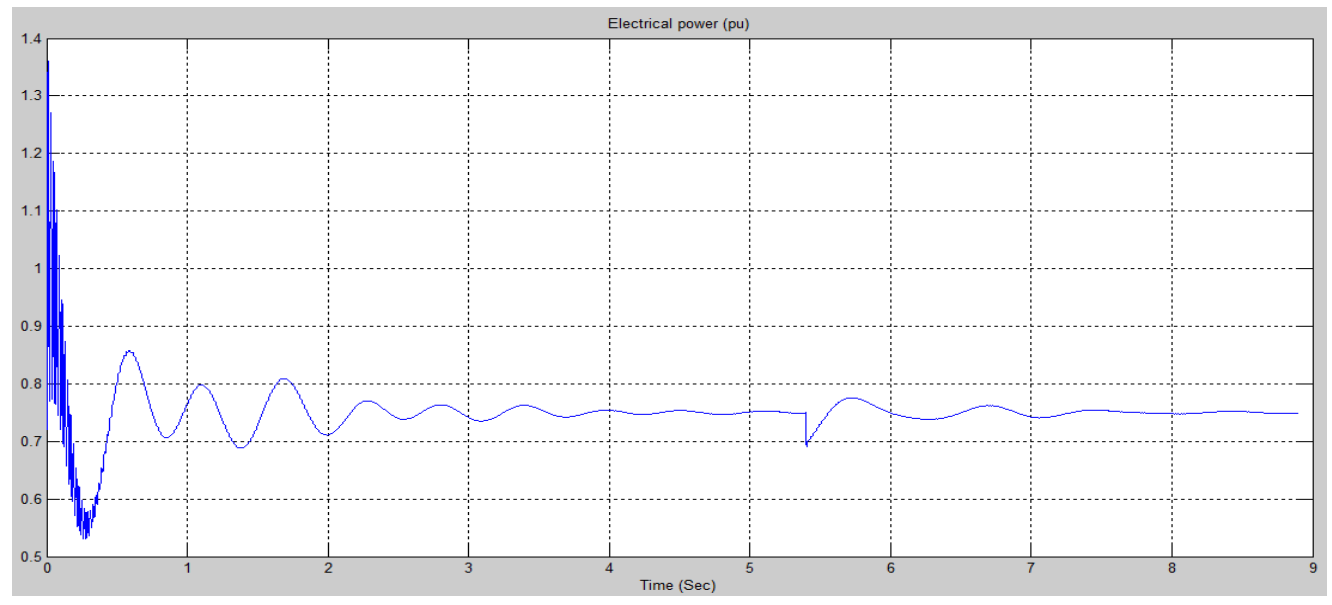

Fig.14. Electrical power Vs time

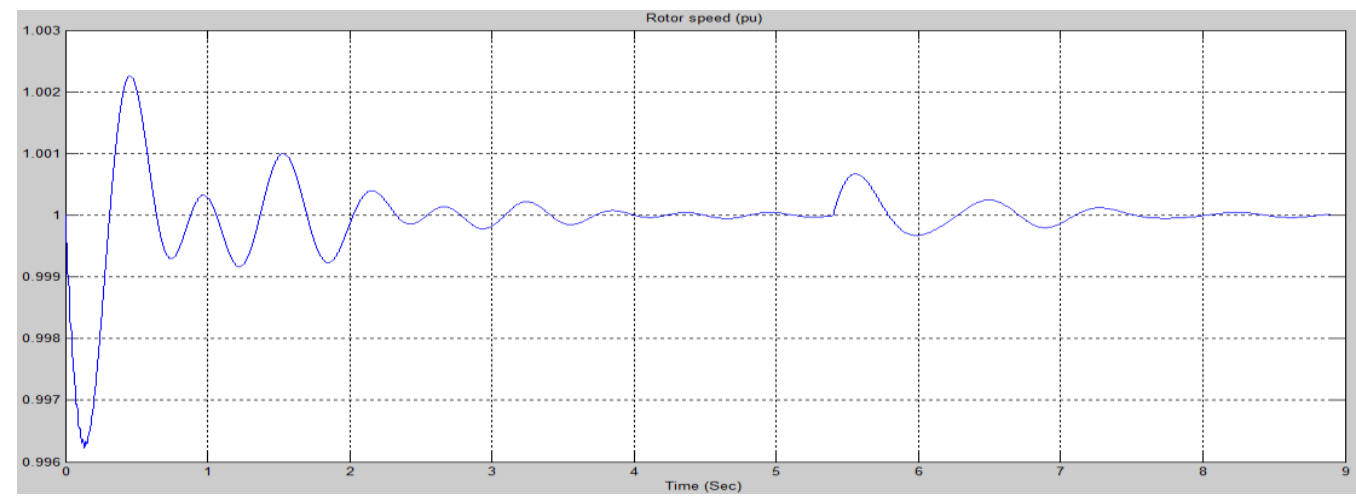

Fig.15. Rotor speed Vs time

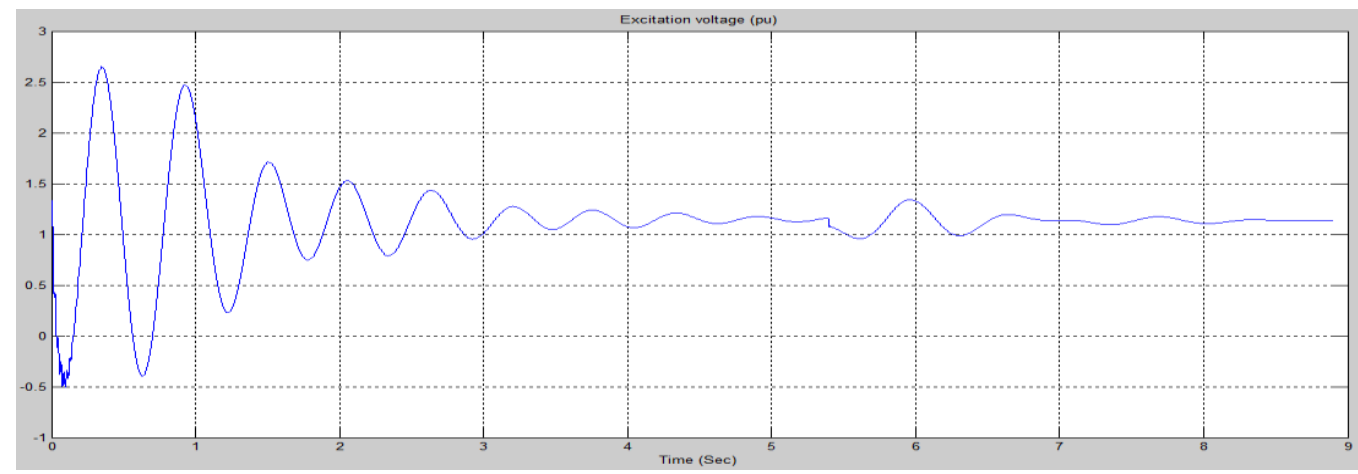

Fig.16. Excitation voltage Vs time 


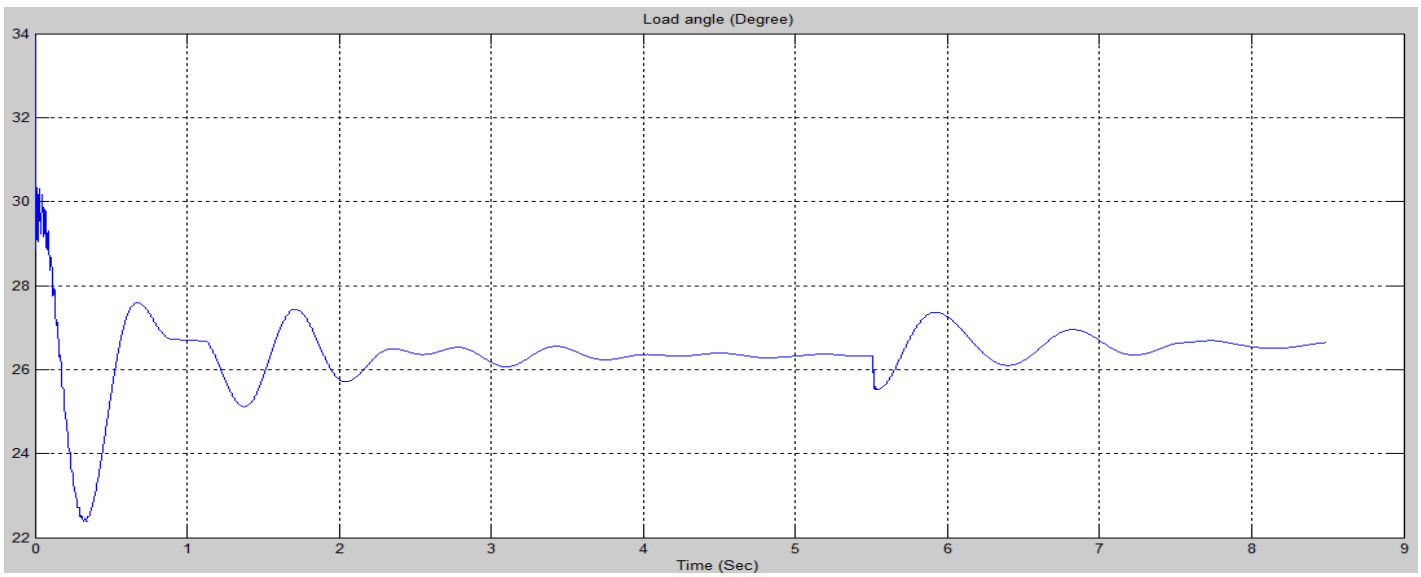

Fig.17. Generator load angle Vs time

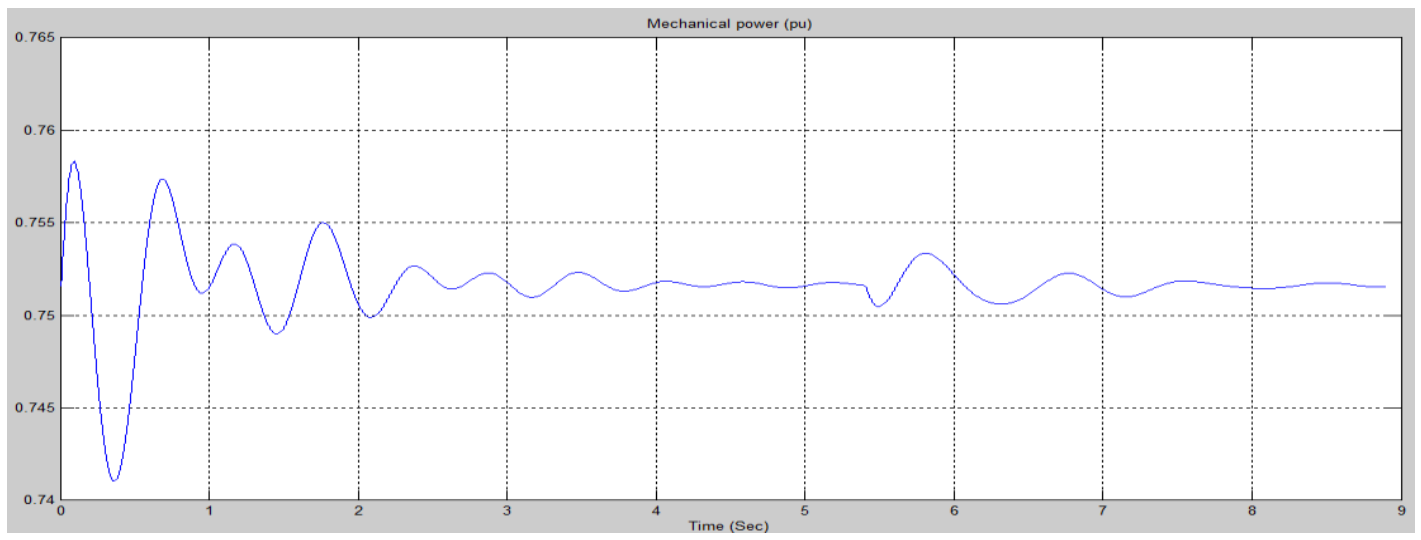

Fig.18. Mechanical power Vs time

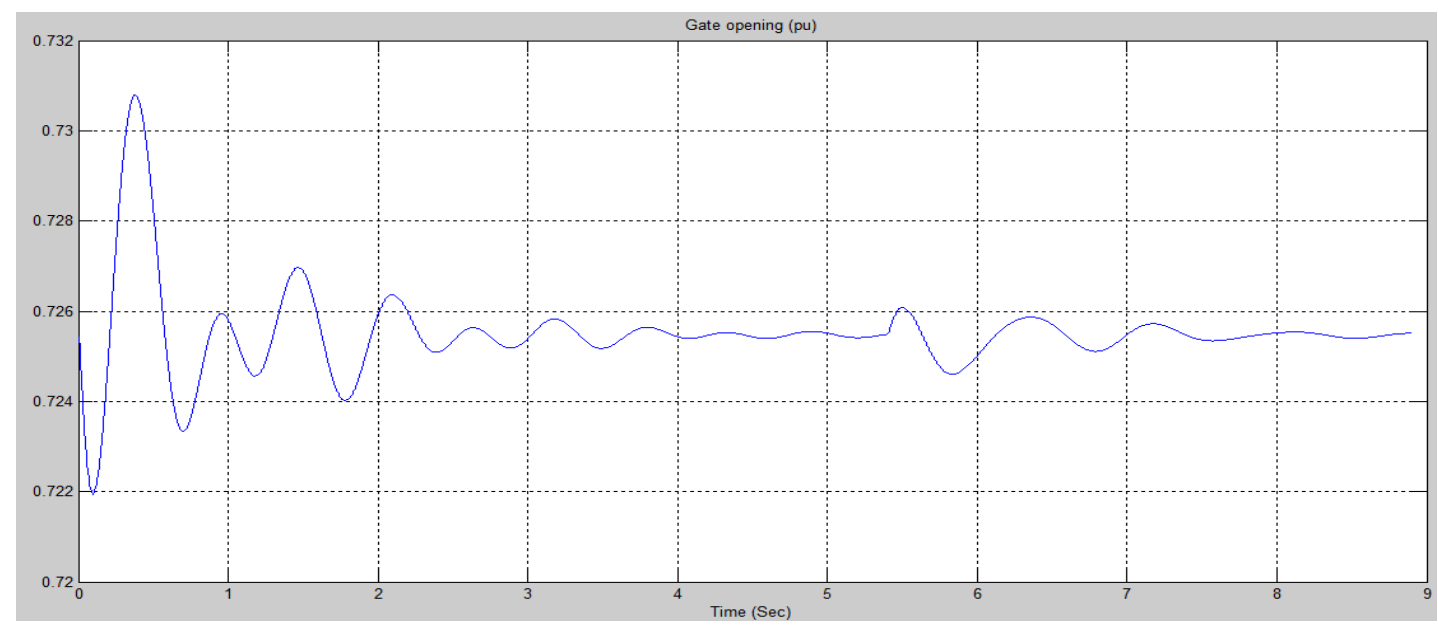

Fig.19. Gate opening Vs time 
Form the obtained simulation results shown above for the reduction of load from the plant, gives the following observations:

1. The electrical power is decreased to 0.7 pu from the initial value of 0.75 pu during the reduction of load and it reached to initial steady state value after 7.0 seconds as shown in Fig. 14.

2. The rotor speed is increased at the time of load reduction but it reached to initial steady state value after 7.0 seconds as illustrated in Fig. 15.

3. There is decrease in excitation voltage to around $1.0 \mathrm{pu}$ at the time of load reduction and it oscillates for about 3.0 seconds and reached to initial steady state value after 8.0 seconds as shown in Fig. 16.

4. There is also decrease in generator load angle to 26 degree from 27 degree at the time of reduction of load and it oscillates for about 2.0 seconds and the initial steady state value is reached after 7.0 seconds as illustrated in Fig. 17.

5. The mechanical power developed is decreased during the reduction of load at $t=5.0$ seconds and it oscillates for about 3.0 seconds and reached to initial steady state after 8.0 seconds as shown in Fig. 18.

6. The gate opening is increased when load is removed from the system and it oscillates for about 2.0 seconds and reached back to initial steady state after 7.0 seconds as shown in Fig. 19.

\subsection{Short Circuit Fault}

The single line diagram for short circuit fault is shown in Fig. 20.

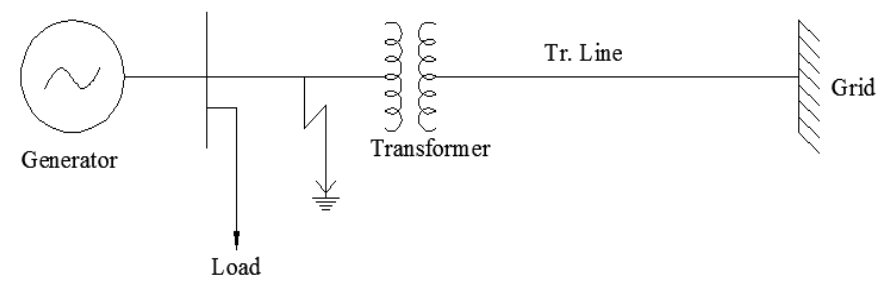

Fig.20. Single Line Diagram for Short Circuit Fault

The disturbance is created by introducing short circuit fault at synchronous generator terminal at time $\mathrm{t}=5.0$ seconds and the fault has been cleared after 0.2 seconds. The simulation is carried for 10.0 seconds. The following characteristics are obtained during short circuit fault at synchronous generator terminal.

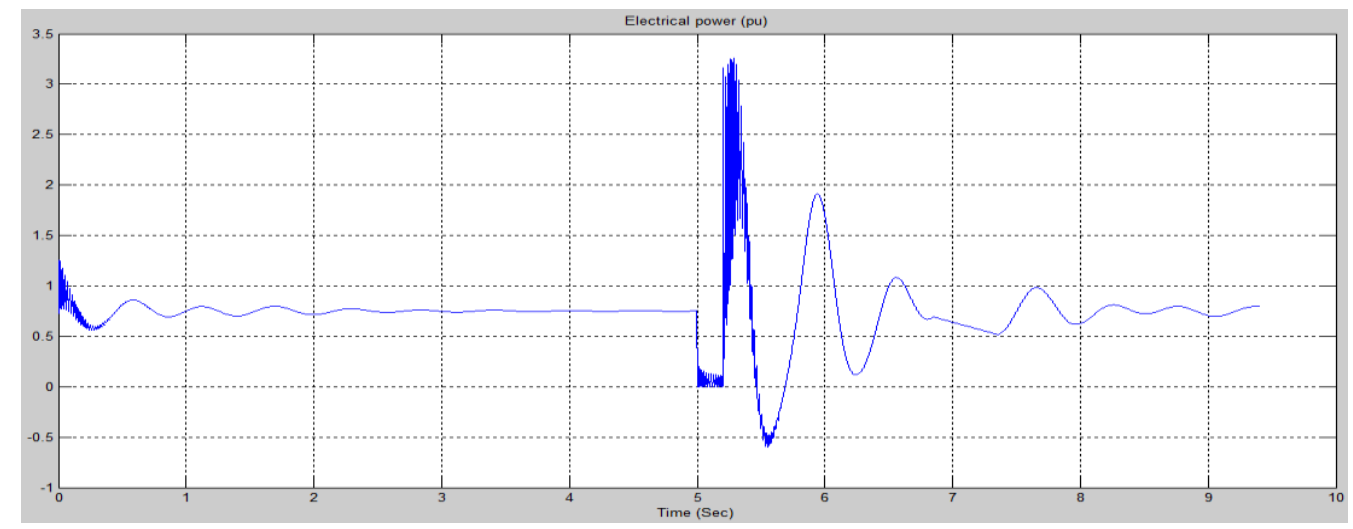

Fig.21. Electrical power Vs time 


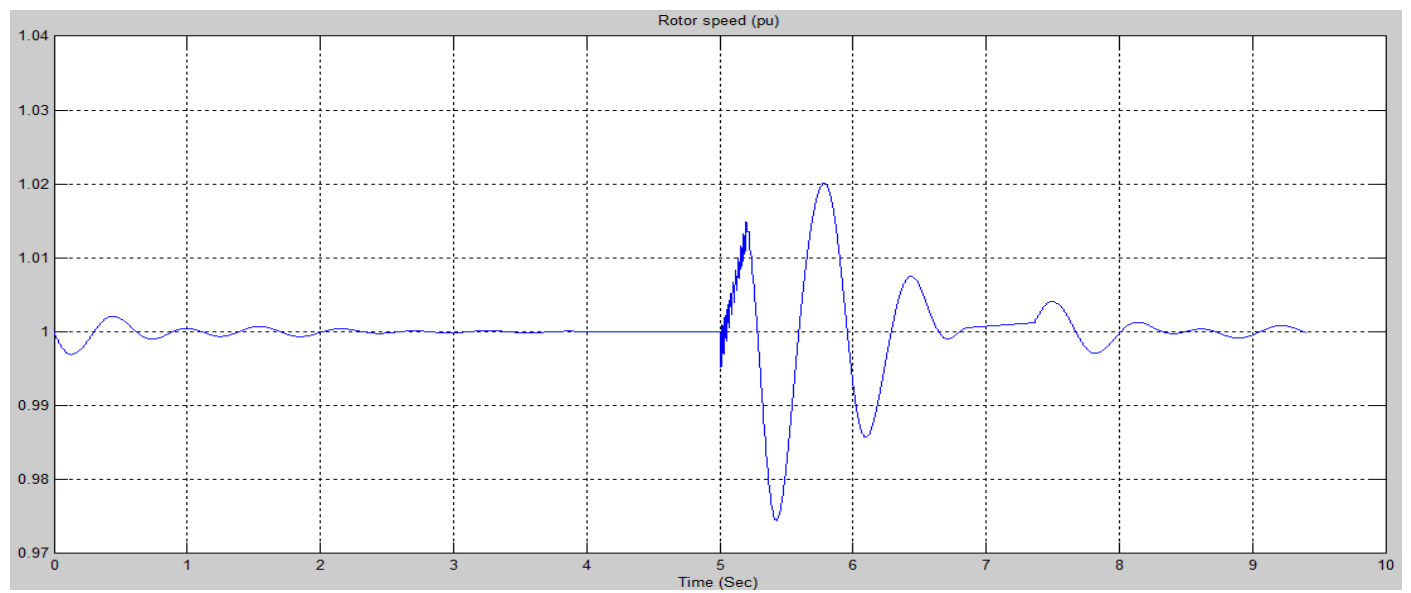

Fig.22. Rotor speed Vs time

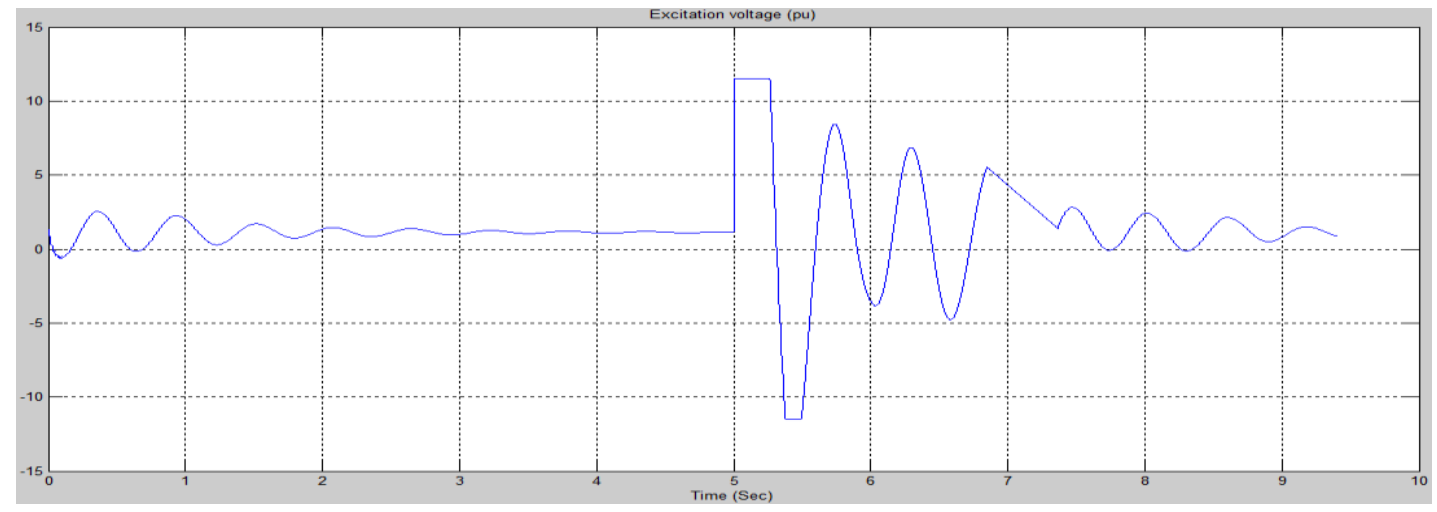

Fig.23. Excitation voltage Vs time

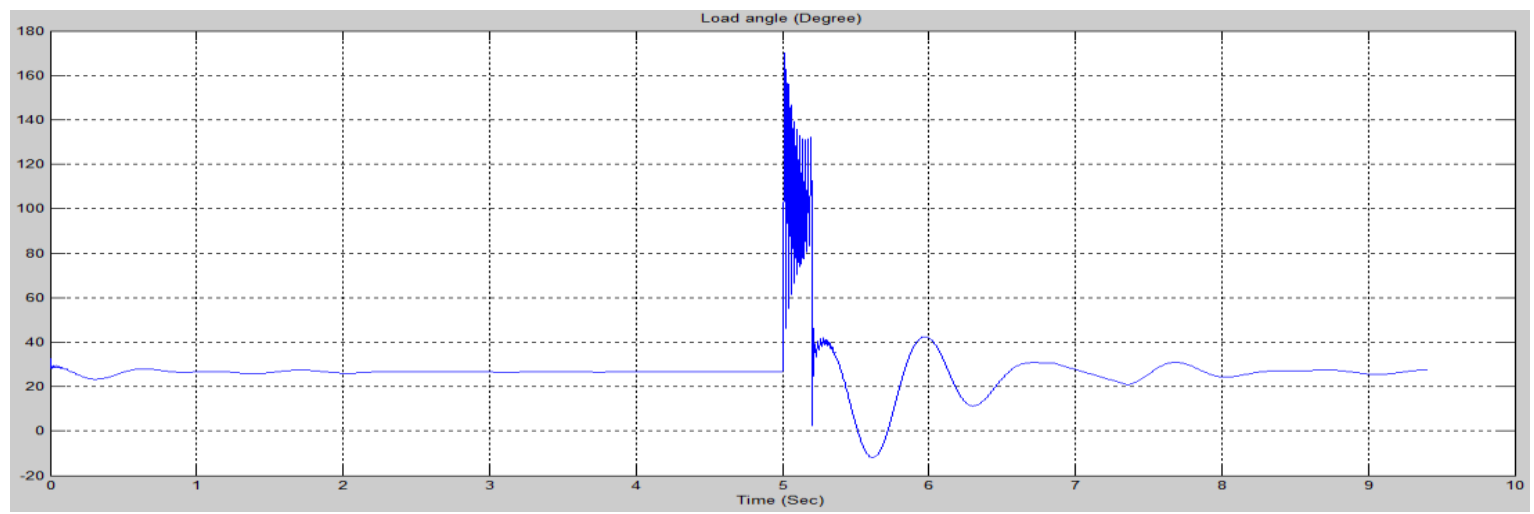

Fig.24. Generator load (degree) angle Vs time 


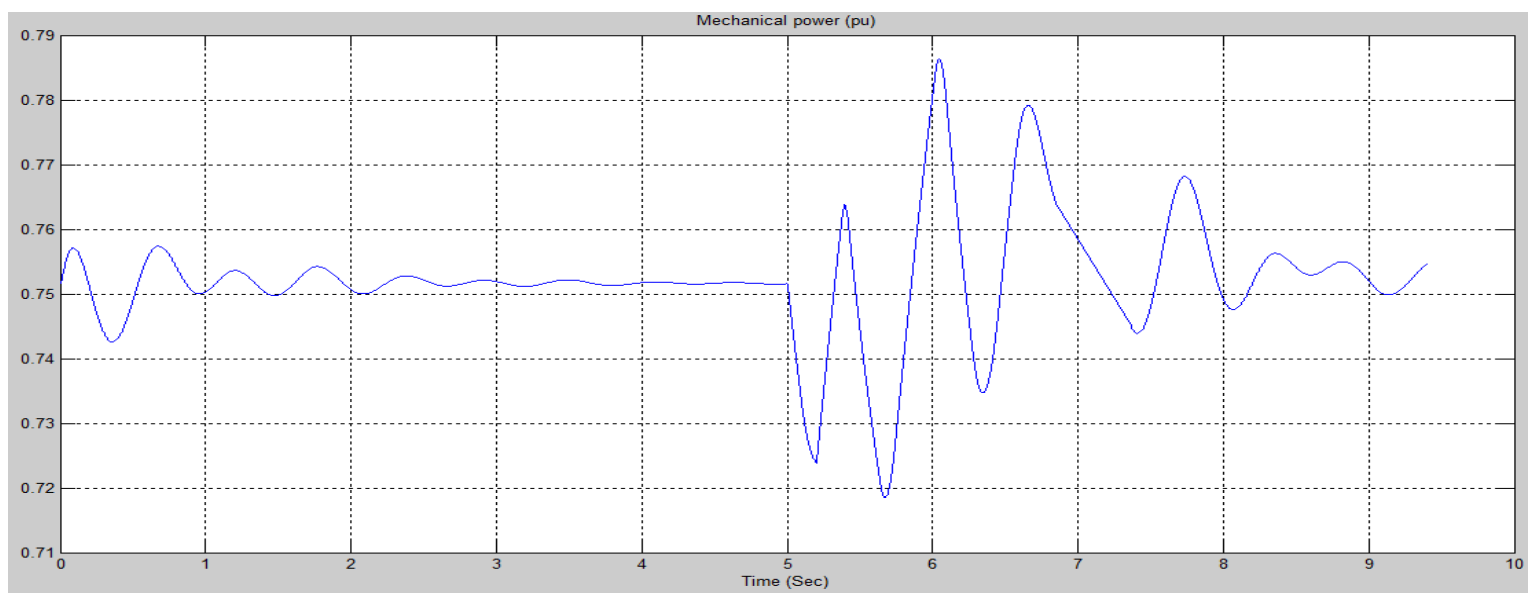

Fig.25. Mechanical power Vs time

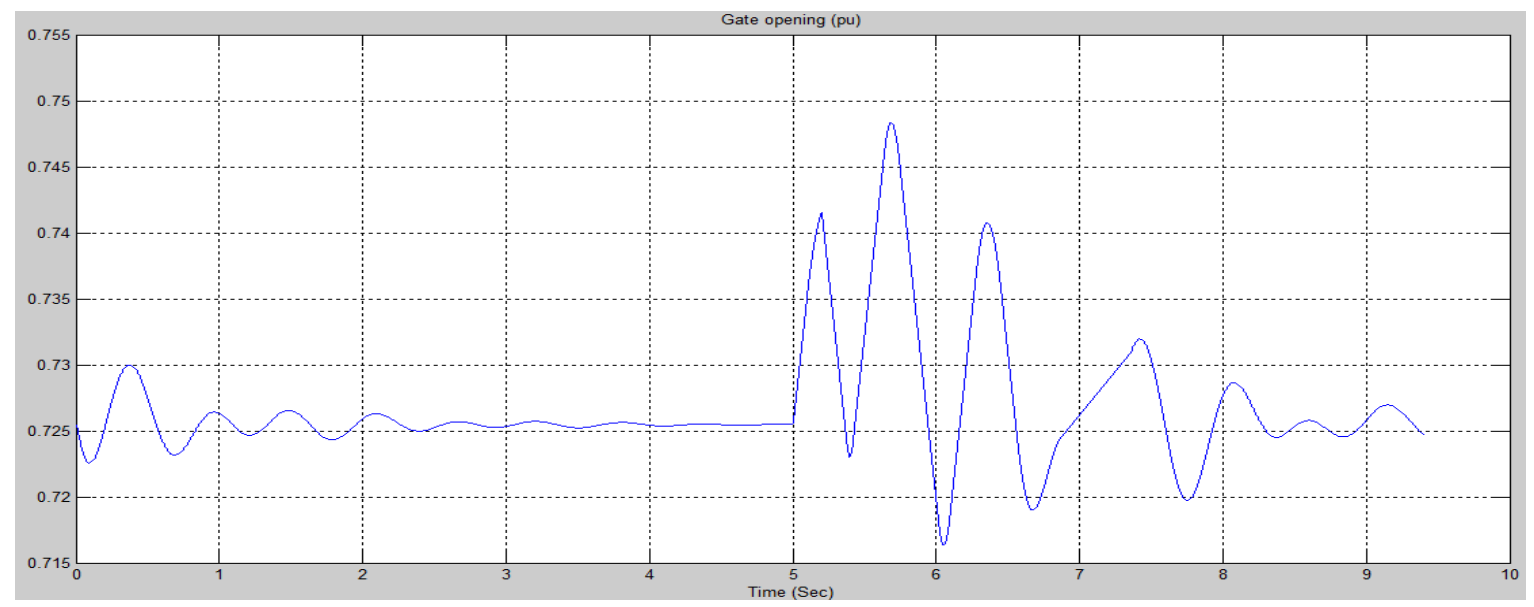

Fig.26. Gate opening Vs time

Form the obtained simulation results shown above for the short circuit fault at synchronous generator terminal, gives the following observations:

1. The electrical power is drops to zero during the fault as shown in Fig. 21 and it oscillates for around 4.0 seconds after the clearance of fault and reached to initial steady state value after 9.0 seconds.

2. The rotor speed is increased to slightly higher than $1.01 \mathrm{pu}$ from the initial value of $1.0 \mathrm{pu}$ during the fault as illustrated in Fig. 22 and it oscillates for around 4.0 seconds and reached to initial steady state value after 9.0 seconds.

3. The excitation voltage is increased highly to an average of $11.5 \mathrm{pu}$ from the initial value of $1.10 \mathrm{pu}$ during the fault as shown in Fig. 23 and it oscillates for around 4.0 seconds and it reached to initial steady state value after around 9.0 seconds.

4. There is significant increase in generator load angle to around 170 degrees from the initial value of 27 degrees at the time of fault as illustrated in Fig. 24 and it oscillates for around 4.0 seconds and reached to the initial steady state value after 9.0 seconds.

5. The mechanical power developed is decreased during the fault and it oscillates for around 4.0 seconds 
and it tends to reached the initial steady state value of 0.751 pu after 9.0 seconds as shown in Fig. 25 .

6. The gate opening is increased to $0.74 \mathrm{pu}$ from the initial value of $0.725 \mathrm{pu}$ during the fault and it oscillates for around 4.0 seconds and it tends to reached initial steady state value after 9.0 seconds as shown in Fig. 26.

\section{Conclusions}

In this paper, a hydro power plant model is developed in Matlab/Simulink environment and then it is transformed to RT-LAB environment to get the real-time simulation data of the hydro power plant. The simulation results demonstrate that in RT-LAB, the real-time simulation of hydro power plant model can be implemented. It is easier to observe the dynamic operating behavior of hydro power plant in RT-LAB than Matlab/Simulink as the corresponding operating parameters can be tuned during the simulation. Moreover, the efficiency of simulation is improved further in RT-LAB and simulation results become more convincing.

\section{References}

[1] N. Kishor, R. P. Saini, and S. P. Singh. A review on hydropower plant models and control. Renew. Sustain. Energy Rev., vol. 11, no. 5, pp. 776-796, 2007.

[2] IEEE Working Group Report. Hydraulic Turbine and Turbine Control Models for System Pynamic Studies. 1992.

[3] Opal-RT Technolgies. RT-LAB User Guide (Version 10.4). Unpublished.

[4] H. Gao and C. Wang, "Effect of detailed hydro turbine models on power system analysis," 2006 IEEE PES Power Syst. Conf. Expo. PSCE 2006 - Proc., no. 50277034, pp. 1577-1581, 2006.

[5] E. De Jaeger, N. Janssens, B. Malfliet, and F. Van De Meulebroeke, "Hydro turbine model for system dynamic studies," IEEE Trans. Power Syst., vol. 9, no. 4, pp. 1709-1715, 1994.

[6] M. Vinatoru and E. Iancu, "The design of control systems for hydraulic turbines. 2006 IEEE Int. Conf. Autom. Qual. Testing, Robot. AQTR, no. 13, pp. 32-36, 2006.

[7] L. G. Scherer and R. F. de Camargo. Control of Micro Hydro Power Stations Using Nonlinear Model of Hydraulic Turbine Applied on Microgrid Systems. Power Electronics Conference (COBEP), pp. 812818, September 2011.

[8] G. Konar, A.K. Singh, and N. Chakraborty. Modeling and Simulation of Standalone Micro HydroDiesel Hybrid Power Plant for Indian hilly Region. Chennai Fourth International Conference on Sustainable Energy and Intelligent Systems, pp. 159-166, December 2013.

[9] F. Hong-qing and S. Zu-yi. Modeling and Simulation of Hydraulic Transients for Hydro Power Plants. IEEE/PES Transmission and Distribution Conference and Exhibition: Asia and Pacific, pp. 1-4, 2005.

[10] O.P. Rahi and G. Kumar. Simulation Studies for Refurbishment and Uprating of Hydropower plants. IEEE/PES General Meeting Conference \& Exposition, pp. 1-5, July 2014.

[11] D. G. Ramey and J. W. Skooglund. Detailed Hydrogovernor Representation for System Stability Studies. IEEE Trans., vol. PAS-89, no. 1, pp. 106-112, January 1970.

[12] H. Zhang, D. Chen, B. Xu, and F. Wang, "Nonlinear modeling and dynamic analysis of hydro-turbine governing system in the process of load rejection transient," Energy Convers. Manag., vol. 90, pp. 128137, 2014.

[13] W. Li, L. Vanfretti, and M. Farrokhabadi. Modeling of Custom Hydro Turbine and Governor Models for Real-Time Simulation. Complex. Eng., pp. 1-6, 2012.

[14] Y. Zhao, L. Shi, Y. Ni, and L. Yao. Modeling and Real-time simulation of wind farm. 2012 Asia-Pacific Power Energy Eng. Conf., pp. 1-4, 2012.

[15] S. Mikkili, A. K. Panda, and J. Prattipati. Review of Real-Time Simulator and the Steps Involved for 
Implementation of a Model from MATLAB / SIMULINK to Real-Time. J. Inst. Eng. India Ser.B "DOI: 10.1007/s40031-014-0128-6", 2014.

\section{Author Profile}

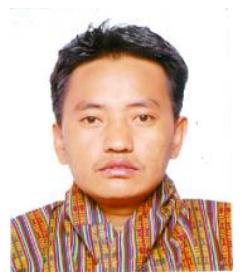

Sonam Dorji was born on March 1985. He received Master of Technology from Indian Institute of Technology Roorkee, India and Bachelor of Engineering in Electrical Engineering from College of Science and Technolgy, Phuntsholing, Bhutan.

In 2011, he joined as faculty at Jigme Namgyel Engineering College (formerly known as Jigme Namgyel Polytechnic), Dewathang, Bhutan. His research interests include modeling and simulation of power system and hydro power plant, renewable energy, smart grid and hybrid energy systems.

How to cite this paper: Sonam Dorji,"Modeling and Real-Time Simulation of Large Hydropower Plant", International Journal of Engineering and Manufacturing(IJEM), Vol.9, No.3, pp.29-43, 2019.DOI: 10.5815/ijem.2019.03.03 